Attitudes about Paid Parental Leave:

Cross-national comparisons and the significance of gendered expectations, family strains, and extant leave offerings

Chris Knoester

The Ohio State University

Qi Li

The Ohio State University

Richard J. Petts

Ball State University

Key words: gendered expectations, family strains, family policy preferences, parental leave

*Please direct all correspondence to Chris Knoester, 152 Townshend Hall, 1885 Neil Ave, The Ohio State University, Columbus, OH 43210 (knoester.1@osu.edu), Ph: 614-247-7261 (work), 614-725-0075 (home), fax: 614-292-6687. Qi Li can be contacted at li.6109@buckeyemail.osu.edu. Richard J. Petts can be contacted at rjpetts@bsu.edu .

***This is the accepted, peer-reviewed preprint version of the article

Knoester, Chris, Li, Qi, and Richard J. Petts. 2021. "Attitudes about paid parental leave: Cross-national comparisons and the significance of gendered expectations, family strains, and extant leave offerings." Online first in International Journal of Comparative Sociology. Copyright (C) [2021] (Sage). https://doi.org/10.1177/00207152211026705 


\begin{abstract}
Using data on paid parental leave preferences from 35,488 adults situated within 26 different OECD countries, and multilevel modeling, this study examines public opinions about the provision of paid parental leave, some government funding of leave offerings, and preferred lengths of leave offerings. We consider how attitudes may be similar or different across social contexts and then focus upon the extent to which gender, gendered parenting role attitudes, family strains, and country-level institutionalized leave offerings are associated with leave preferences. The findings indicate that the vast majority of respondents are in favor of rather widespread and generous paid parental leave offerings; indeed, there are generally high levels of support for paid leave availability, relatively long paid leave offerings, and government funding of leaves. Gendered expectations and family strains are consistently associated with individuals' leave preferences-even after accounting for country-level social contexts. Country-level offerings are also associated with leave preferences-- yet we find that the overwhelming majority of respondents express a desire for paid parental leave length offerings that are substantially different than the extant leave offerings in their country. Overall, this research complements previous work by newly documenting widespread public support for the provision of paid leave and some government funding of it. Also, it establishes that gendered expectations, family strains, and country-level practices are consistently associated with paid parental leave preferences in wealthy countries. Yet, substantial dissatisfaction with extant paid leave policies within countries seems to be commonplace.
\end{abstract}

Key words: gendered expectations, family strains, family policy preferences, parental leave 


\section{Attitudes about Paid Parental Leave: Cross-national comparisons and the significance of gendered expectations, family strains, and extant leave offerings}

Paid parental leave, commonly understood as paid time off from work for the purpose of parenting a new child, is beneficial to families (Koslowski et al., 2019). Access to paid parental leave improves family finances (Isaacs, Healey, and Peters, 2017; Stancyzk, 2016) and helps parents develop strong attachments to infants (Cooklin, Rowe, and Fisher, 2012; Pragg and Knoester, 2017). It is associated with positive health and developmental consequences for mothers (Aitken et al., 2015; Avendano et al., 2015; Chatterji and Markowitz, 2012) and infants (Stearns, 2015; Tanaka, 2005). Especially when it is neither particularly short (e.g., less than 20 weeks) nor long (e.g., more than 30 weeks), paid leave encourages and allows mothers to continue participating in the labor force after a birth (Akgunduz and Plantenga, 2013; Ferragina, 2020; Keck and Saraceno, 2013). Moreover, fathers who utilize leave offerings may invest more in their family life (Ferragina, 2020; Haas and Hwang, 2008; Pragg and Knoester, 2017). Despite the benefits of paid parental leave-taking for both parents, mothers take advantage of parental leave benefits more regularly than fathers-- seemingly due to institutionalized offerings that are more focused on mothering as well as the related influences of gendered identities, expectations, and divisions of labor that continue to urge mothers to prioritize domestic labor and fathers to prioritize paid labor (Duvander, 2014; Haas and Hwang, 2019; Li et al., 2021).

Still, paid parental leave-taking opportunities exist throughout much of the world for mothers and fathers. All but seven economies (i.e., the Marshall Islands, the Federated States of Micronesia, Palau, Papua New Guinea, Suriname, Tonga, and United States) provide paid maternity leave. Also, $42.5 \%$ of nations (and 94\% of OECD countries) either allow fathers to utilize paid parental leave or offer fathers paid paternity leave, specifically (International Labor 
Organization, 2014; Raub et al., 2018; World Bank Group, 2018). Yet, there is tremendous variation in the lengths and features of paid parental leave offerings (Boeckmann et al., 2015; Koslowski et al., 2019). Also, many individuals express dissatisfaction with their paid parental leave offerings (Knoester and Li, 2021; Li et al., forthcoming; 2021; Valarino et al., 2018).

Such uneven access to, and dissatisfaction with, paid parental leave offerings across nations prompts questions about how much agreement exists about paid parental leave offerings cross-nationally, and how these attitudes match up with extant country-level policies. Also, what are the primary individual-level factors that shape attitudes about paid parental leave offerings? Parental leave preferences are important because policymakers and political representatives may wish to respond to individual preferences — for quality of life aspirations as well as political advancement opportunities. Yet, the relationship between attitudes and instituted policies is bidirectional; policy preferences shape policies and vice versa (Brooks and Manza, 2006; Campbell, 2012; Gangl and Ziefle, 2015; Manza and Cook, 2002). Thus, we would expect to find some concordance between extant leave policies and leave preferences. Related to this, parental leave preferences and the significance of extant leave policies may depend upon more complete explicit family policy packages that also include country-level approaches to the provision of child care, early childhood education, and child-income (Daly and Ferragina, 2018; Ferragina, 2019; 2020).

Further, while previous research offers descriptions of the benefits and patterns of paid parental leave practices across countries, scholars have yet to comprehensively document the extent to which especially prominent social forces that are connected to leave-taking decisions and preferences-- such as gendered expectations, family strains, and extant offerings at the country-level-- may contribute to public opinions about leave offerings across countries. 
Comparatively more research has focused on better understanding the effects of parental leave policies for individuals rather than on individuals' preferences for paid leave offerings across countries and how such preferences may vary by individuals' unique country contexts (Daly and Ferragina, 2018; Ferragina, 2019; 2020; Misra and Boeckmann, 2016; Olivetti and Petrongolo, 2017; Petts et al., 2018; Valarino et al., 2018). Therefore, there is a need to complement inquiries that focus on dynamics within particular countries with more wide-ranging foundational analyses of individuals' paid leave preferences and the country-level and individual-level factors that shape them (Daly and Ferragina, 2018; Li et al., 2021; Valarino et al., 2018).

Consequently, the purpose of this study is to analyze attitudes about paid parental leave across 26 OECD countries and among more than 35,000 individuals. In our analysis, we begin by describing attitudes about some basic features of paid leave offerings: Should paid leaves be provided? Should they be supported by at least some government funding? How long should the leave offerings be? To what extent do these attitudes align with the extant paid parental leave offerings within one's country of residence? Although paid parental leave offerings are nearly universal and some government funding of them is common, it is still useful to document the extent to which individuals in different countries support these family policy features - there may be some resistance or backlash to them, for example. Also, of course, not all countries have embraced paid leave offerings and some government funding for them; most notably, the U.S. does not offer any statutory paid leave. Is support for paid leave and some government funding for it dramatically different in the U.S. compared to so many other countries? Regardless, more extensive variance is anticipated to exist between individuals' desires for lengths of leave offerings; particularly given the many different approaches to implementing paid parental leave offerings as part of explicit family policies within different nations. These different approaches 
may influence individuals' sense of the appropriateness of different lengths of leave offerings (Daly and Ferragina, 2018; Ferragina, 2019; 2020; Koslowski et al., 2019; Li et al., 2021; Valarino et al., 2018). Therefore, as part of our descriptive analysis, we also investigate the extent to which expressed paid parental leave preferences are mismatched with country-level paid parental leave offerings, in an attempt to identify where policy changes may be needed.

Then, we move to multilevel regression analyses and highlight a gender perspective by emphasizing the implications of gendered expectations for paid parental leave preferences. Yet, we also anticipate that family strains and extant family policies within countries are relevant to shaping support for the availability of paid parental leaves, particular lengths of leave offerings, and government funding of leaves. Although there is good reason to anticipate that preferences for leave offerings may depend on gendered expectations, recognitions of family strains, and extant leave offerings at the country-level, there is a lack of evidence of the extent to which these factors are associated with attitudes about basic features of paid leave offerings across different social contexts (Knoester and Li, 2021; Li et al., forthcoming; 2021; Valarino et al., 2018). Thus, the present study can offer important and novel information that can improve our understandings of the factors that lead individuals to establish particular preferences for paid leave offerings. This information may then be useful for supporting and responding to different gendered or family-based preferences, for example.

To accomplish our analytic goals, we use data about leave preferences from the 2012 wave of the International Social Survey Programme (ISSP) and complement this with OECD and World Bank reports of 2012 country-level characteristics. We extend the sparse previous work on leave preferences by: a) more comprehensively considering gendered expectations, family strains, and country-level contexts, b) analyzing a larger sample that encompasses respondents 
from twenty-six OECD countries, c) using a richer set of individual-level predictors, d) considering a broader range of country-level predictors (i.e., that indicate women's equality, childbearing trends, the wealth of a nation, explicit family policy expenditures, and democracy levels), e) using multilevel modeling techniques to better understand the determinants of attitudes towards paid parental leave, and f) offering an estimate of mismatches between individual preferences and extant country-level leave offerings.

\section{Conceptual Framework}

The conceptual framework for this study is informed by a gender perspective, role theory insights into how family, work, and social contexts may matter for leave preferences, and public opinion about family policy research. First, we emphasize gendered expectations and the evolution of paid parental leave offerings as key to understanding paid parental leave preferences. Specifically, we focus on gendered identities and attitudes about (gendered) parenting roles in shaping extant offerings and preferences for parental leave availability, length of leave offerings, and government funding of leaves. This focus draws upon the recognition of gender as structure that shapes life experiences, values, and aspirations; still, gender as structure is also continually being challenged and its implications are received, negotiated, and often contested (Ridgeway, 2009; Risman, 1998; West and Zimmerman, 1987).

Gendered attitudes, identities, and expectations are intertwined and enmeshed within gendered cultures that disproportionately direct and encourage women to embrace childrearing and other domestic tasks (Boeckmann et al., 2015; Hays, 1996; Risman, 1998). They are also institutionalized and continually reinforced — but can be challenged and frequently are — as gender is “done” (Acker, 1990; Ridgeway, 2009; Risman, 1998; West and Zimmerman, 1987). Individuals are often mindful of these gendered attitudes and expectations, even if they do not- 
or are not—able to put them into practice (Hays, 1996; Hook, 2006; Li et al., 2021; Stier et al., 2001). Regardless, such gendering processes occur almost automatically and serve as frames for how we see the world and ourselves, behave, and interact with others (Ridgeway, 2009; Risman, 1998). Thus, gendered expectations are expected to influence paid parental leave preferences. Second, we draw from role theory (e.g., Biddle, 1986; Goode, 1960) assumptions about not only how gender might matter for leave preferences, as gender is institutionalized as well as done, contested, and negotiated in terms of its implications for (gendered) parenting roles; but, also how extant policy contexts and family strains may influence leave preferences. That is, leave preferences are understood to be extensions of family, work, and social life role expectations that emerge out of the supports, cultures, and strains that are perceived to exist and are experienced differently across policy and family contexts. For example, extant policy contexts may encourage support for the status quo because they may symbolize normative expectations within a country (Campbell, 2012; Gangl and Ziefle, 2015; Keck and Saraceno, 2013). Also, the realized or anticipated role strains, conflicts, and potential overloads of caring for children and optimizing productivity in paid labor — as they are experienced, in part, as a function of country-level and family contexts-- are expected to be positively associated with preferences for more generous and widespread paid parental leave offerings. This is because generous and widespread paid parental leave offerings may provide valuable means to alleviate role strains, conflicts, and broader demands that accompany family life after the arrival of a new child (Biddle, 1986; Goode, 1960; Petit and Hook, 2005; Valarino et al., 2018; Yavorsky et al., 2015).

Finally, we integrate public opinion about family policy research that notes the influence of institutional, self-interest, and ideational factors in predicting policy preferences (Blekesaune 
and Quadagno, 2003; Li et al., 2021; Valarino et al., 2018). Institutional factors refer to practices and structures within different national contexts, self-interest refers to the influence of how one benefits or anticipates benefitting from welfare policies, and ideation refers to subjective perceptions that involve attitudes, ideologies, or perceptions of need (Blekesaune and Quadagno, 2003; Li et al., 2021; Valarino et al., 2018).

\section{Gender and Paid Parental Leave Preferences}

Paid parental leave offerings primarily emerged as efforts to enhance mother and child health outcomes due to the health risks and pains associated with childbirth as well as expectations that mothers primarily care for children after birth (Daly and Ferragina, 2018; Koslowski et al., 2019; Olivetti and Petrongolo, 2017; World Bank Group, 2018). Yet, paid leave offerings have also been increasingly designed with a variety of employment outcome and gender equity goals in mind; some paid leave is viewed as essential in supporting mothers' employment opportunities, but too much paid leave can dampen particularly less-educated mothers' employment commitments (Akgunduz and Plantenga, 2013; Boeckmann et al., 2015; Budig et al., 2015; Daly and Ferragina, 2018; Ferragina, 2019; Keck and Saraceno, 2013; Olivetti and Petrongolo, 2017).

Thus, paid parental leave offerings have also been increasingly implemented with the intent to offer greater flexibility for families to manage paid and domestic work commitments and to encourage not only mothers, but also fathers, to spend time caring for and bonding with their children. To promote fathers' take-up of leave, a portion of leave offerings are now commonly reserved for them (Daly and Ferragina, 2018; Ferragina, 2020; Koslowski et al., 2019; O’Brien, 2009). Overall, parental leave offerings can be seen as investments in quality of

life experiences, child development, and family well-being — with more recent and yet emerging 
support for more flexible gendered family arrangements, the promotion of fathers' family care work, and the explicit promotion of women's employment commitments and statuses. All affluent countries with the exception of the U.S. offer some form of paid parental leave; most offer at least six months of well-paid (i.e., $>66 \%$ of earnings) leave and offer flexibility as to who can take the leave. Leave that is reserved for fathers is becoming more common but is typically only a small fraction of the total paid leave that is offered (Daly and Ferragina, 2018; ILO, 2014; Koslowski et al., 2019). Therefore, minimally, there is good reason to anticipate that most individuals across different nations are supportive of paid leave and some government funding of paid leave — even in the U.S., according to previous research. Yet, such public opinions have not been documented (Li et al., 2021; Valarino et al., 2018). Also, since three months of maternity leave was common by the 1980s and there has been growth in more flexible parental leave offerings and leave that is specifically reserved for fathers since then, we anticipate rather generous but varying preferences for lengths of paid leave offerings, dependent on a host of institutional, cultural, and individual factors - including the gendered expectations, (gendered) parenting role attitudes, family strains, and country-level contexts that we investigate in the present study (Daly and Ferragina, 2018; Ferragina, 2019; 2020; Petit and Hook, 2005).

Nonetheless, paid parental leave is still predominantly viewed as a "women's" or a "family" issue," with more tangential implications for men in the majority of social contexts (Ferragina, 2020; Hays, 1996; O’Brien, 2013; Thébaud and Pedulla, 2016). Gendered attitudes, identities, and expectations in society, and within individuals (e.g., Hays, 1996; Risman, 1998; 2004; Senior, 2014), suggest that compared to men, women are anticipated to be especially likely to support paid parental leave, longer lengths of leave, and government support in funding leaves in order to make them more readily available; paid leave offerings continue to be viewed as less 
salient for men (Daly and Ferragina, 2018; Duvander, 2014; Ferragina, 2020; Li et al., 2021; Valarino et al., 2018).

On average, gendered expectations function to disadvantage women by dismissing their unpaid labor as unworthy of compensation and "natural", while disproportionately encouraging and rewarding men's paid labor (Akgunduz and Plantenga, 2013; Boeckmann et al., 2015; Hays, 1996; Thébaud and Pedulla, 2016). Of course, men can express dissatisfaction with gendered attitudes, identities, and expectations and voice support for paid parental leave, as well. In fact, increasing numbers of men appear to be doing so (Duvander, 2014; Petts et al., 2018; Valarino et al., 2018). Moreover, traditionally gendered attitudes, identities, and expectations are not always embraced and are sometimes resisted or modified, in unique ways. Indeed, individuals express an increasing variety of opinions and are often ambivalent about gendered attitudes (Cotter et al., 2011; Knight and Brinton, 2017; Li et al., forthcoming; 2021).

Nevertheless, for the most part, women appear especially likely to benefit from paid parental leaves and their support for it may reflect self-interest. Clearly, women provide the vast majority of child care and need recovery time after a birth (Bianchi et al., 2006; Hook, 2006; O’Brien, 2013; Yavorsky et al., 2015). In addition, they are more likely than men to forego career advancements and uninterrupted commitments to paid labor when a new child arrives (Duvander, 2014; Senior, 2014; Yavorsky et al., 2015). Still, women are disproportionately more likely to attempt to equally balance domestic and paid labor responsibilities (Bianchi et al., 2006; Boeckmann et al., 2015; Hays, 1996; Senior, 2014). Accordingly, previous research suggests that women are more supportive of longer paid parental leaves and are more likely to take them, compared to men (Duvander, 2014; Petts et al., 2018; Valarino et al., 2018). Largely, this appears to be a function of gendered expectations that individuals receive and somehow 
internalize, process, and negotiate; also individuals seem prone to adopt views that are consistent with their own self-interests.

\section{Gendered Attitudes about Parenting Roles and Paid Parental Leave Preferences}

Gendered attitudes about parenting roles are also likely to affect paid parental leave preferences. There is evidence of a shift toward more egalitarian gender attitudes in many countries between the 1970s to the 1990s, at least (Cotter, Hermsen, and Vanneman, 2011; Goldscheider et al., 2015). Yet, recent work has also noted that gender ideologies are increasingly, and best understood as, multidimensional (Cotter et al., 2011; Davis and Greenstein, 2009; Grunow et al., 2018; Knight and Brinton, 2017). Thus, we consider multiple dimensions of gendered attitudes about parenting roles in our attempts to better understand leave preferences, focusing on attitudes about dual-earning expectations, separate spheres of expertise and devotion, and intensive mothering. These attitudes can be, and often are, combined in myriad ways (e.g., support for sole or dual-income breadwinning that may or may not include part-time work; support for separate spheres may be understood as over and beyond any of the breadwinning combinations; intensive mothering may be combined with any of the breadwinning and separate spheres expectations).

First, dual-earning expectations may be relevant for paid leave attitudes (Li et al., forthcoming; 2021; Valarino et al., 2018). If more egalitarian expectations or preferences for a dual-earner family structure exist, then individuals may be more supportive of paid parental leave opportunities and funding because leaves can alleviate work-family conflicts and support women's labor force participation (Raub et al., 2018; World Bank Group, 2018). In contrast, if an expected or preferred outcome is to have a sole, male breadwinner, then individuals may be less likely to support the availability and funding of paid parental leave. That is, they may view 
paid leave as functioning to keep women in paid labor, through a retention enticement—and a misuse of collective resources. Nevertheless, it may be that those with an expectation or preference for a male, sole breadwinner family structure may support longer paid parental leaves than those with a preference for a dual-earner family structure. Longer leaves may allow for longer spells of male, sole breadwinning for families that could not otherwise enact this family structure. In contrast, more modest lengths of leaves may better support women's employment, occupational status, and aspirations for advancement—which may be a priority among those with more egalitarian breadwinning preferences (Boeckmann et al., 2015; Knight and Brinton, 2017; Naldini et al., 2016; Stier et al., 2001; Valarino et al., 2018).

Regardless, gendered preferences for separate spheres specialization may be linked to paid parental leave attitudes, also (Li et al., forthcoming; 2021; Valarino et al., 2018). Specifically, expectations and preferences for women to be primarily homemakers and child caregivers and men to be invested in paid labor may discourage support for paid parental leave and the funding of it, on average, but it may also lead to support for especially long paid parental leave spells, as well—with the assumption that women would be taking the long leaves in order to practice traditionally gendered specializations (Budig et al., 2016; Hook, 2006; Naldini et. al., 2016; Valarino et al., 2018).

Finally, intensive mothering expectations and preferences may predict attitudes about paid parental leave (Hays, 1996; Li et al., forthcoming; 2021; Stier et al., 2001; Valarino et al., 2018). Proponents of intensive mothering, which involves the general belief that mothers are essentially different than fathers and should seek to do all that they can to engage with their children and nurture their development, may also be less supportive of parental leave availability and the funding of it. Intensive mothering expectations and attitudes have often led to pressures 
and motivations for mothers to exit the labor force and focus upon raising their childrenespecially when they are young (Hays, 1996; Knoester and Fields, 2020; Li et al., forthcoming; 2021). Yet, advocates for intensive mothering may also be inclined to support the availability of especially long leaves, too. Long parental leaves may allow for intensive mothering for extended periods of time by mothers who would otherwise have to, or be expected to, work in paid labor (Hook, 2006; Stier et al., 2001). Still, proponents of more generalized intensive parenting practices, that are not gender-specific and may include intensive fathering, may also support longer leave offerings because a combination of mothers and fathers taking leave could elongate windows of time for intensive parenting, without paid work commitments (Daly and Ferragina, 2018; Knoester and Li, 2021; Koslowski et al., 2019).

Gendered attitudes about dual-earning, separate spheres, and intensive mothering may also work in unique combinations with one another in predicting support for paid parental leave. For example, we expect that dual-earning expectations will determine the extent to which separate spheres and intensive mothering attitudes matter. That is, support for more widespread and generous paid paternity leave offerings may be highest when one's preference is to encourage dual-earning and challenge traditionally gendered separate spheres and intensive mothering practices. Yet, support for leave is also likely to be substantial even if one embraces separate spheres and intensive mothering ideals - if one also supports dual-earning expectations. Also, a combination of attitudes that reflect ideals for separate spheres and intensive mothering may particularly encourage reduced enthusiasm for the provision and funding of leaves but also desires for longer paid parental leaves to enact gendered parenting role preferences.

Family Strains and Paid Parental Leave Preferences 
Nevertheless, recognitions of the need for substantial economic resources to raise children and of the stresses that work-family conflict offer are expected to encourage appreciation for the usefulness of paid parental leaves. As role theories emphasize, caring for children while also working elevates role strains, conflicts, and overloads (Collins, 2019; Goode, 1960; Olivetti and Petrongolo, 2017; Yavorsky et al., 2015). Children are expensive and the absence of widespread and at least moderately generous paid parental leave offerings can reduce the ability for continued, uninterrupted breadwinning (Koslowski et al., 2019; Olivetti and Petrongolo, 2017; Petit and Hook, 2005; World Bank Group, 2018). In addition, after the arrival of a new child, there are enormous and exhausting additions to domestic work responsibilities (Collins, 2019; World Bank Group, 2018; Yavorsky et al., 2015). Thus, family-related strains and ideations that reflect perceptions of need, such as those involving the cost of childrearing and work-family conflict, are expected to be positively associated with support for paid parental leaves, longer leaves, and government funding for leaves.

\section{Gendered Expectations, Institutional Contexts and Paid Parental Leave Preferences}

Still, country-level contexts are expected to shape paid parental leave preferences_-and respond to them. This may occur through policy responses to public opinions about paid parental leave offerings (Brooks and Manza, 2006; Li et al., 2021; Manza and Cook, 2002), or policy feedback mechanisms may result in instituted policies influencing public opinions, expectations, and behaviors (Campbell, 2012; Gangl and Ziefle, 2015). For example, country-level indicators of female empowerment and fertility rates may influence paid parental leave preferences because they may reflect gendered expectations for work and family roles (Ferragina and Seeleib-Kaiser, 2015; Manza and Cook, 2002; O’Brien, 2013; Valarino et al., 2018; Winter, 2008). Furthermore, social spending allocations to families-- such as through cash benefits, tax policies, childcare, 
and early childhood education-- are important factors in determining the contexts for leave and paid work decisions and opportunities (Boeckmann et al., 2015; Budig et al., 2016; Olivetti and Petrongolo, 2017). Finally, levels of democracy may determine the extent to which the will of the people is assumed and expected to matter, for policy outcomes (Campbell, 2012; Hook, 2006; Knight and Brinton, 2017; Stier et al., 2001).

\section{Other Factors}

Other individual factors linked to gendered expectations, family strains, and country-level contexts that may also predict paid parental leave preferences include age, education, and paid and unpaid work commitments (Collins, 2019; Cotter et al., 2011; Ferragina, 2019; 2020; Keck and Saraceno, 2013; Li et al., 2021). Family structure contexts may also matter as more institutionalized partnerships and the presence of children may be associated with perceptions, and experiences, of need (Boeckmann et al., 2015; Duvander, 2014; Petts et al., 2018). Thus, we consider these factors to be confounding influences for our focus on gendered expectations, family strains, and paid parental leave preferences.

\section{Hypotheses}

Our conceptual framework and previous research lead to four main hypotheses:

$H_{1}$ : Support for widespread and generous paid parental leave will be common, but compared to men, women will be more likely to support the availability of paid parental leave, longer lengths of leave, and government support for leaves.

$H_{2 a}$ : Dual-earning expectations will be positively, and support for separate spheres and intensive mothering will be negatively, associated with preferences for more widespread and generous paid parental leaves. 
$H_{2 b}$ : We anticipate that these gendered attitudes about parenting roles will interact with each other in shaping support for paid parental leave. That is, we expect that dual-earning expectations will determine the extent to which attitudes about separate spheres and intensive mothering lead to support for paid parental leave availability; support will be markedly higher if dual-earning expectations are embraced. In addition, we anticipate that traditionally gendered attitudes about separate spheres and intensive mothering will combine to significantly enhance preferences for longer lengths of paid parental leave and dampen support for paid parental leave availability and government funding of leaves.

$\mathrm{H}_{3}$ : The recognition of family strains will be related to paid parental leave preferences. Specifically, noting that childrearing incurs great expense and experiencing work-family conflict are likely to be positively associated with support for the availability of paid parental leave, longer lengths of leave, and government support for leaves.

$\mathrm{H}_{4}$ : Country-level lengths of paid parental leave offerings will be positively associated with individuals' preferences for more generous and widespread paid parental leave offerings.

\section{Data and Methods}

We use data from the International Social Survey Programme (ISSP) 2012. The data contain information from over 40 countries across Asia, North America, South America, Europe, Oceania, and Africa. Data collection occurred between 2011 and 2013 (Scholz et al., 2014). This wave of the ISSP is particularly well-suited for our purposes because it uniquely asks about paid parental leave preferences.

Our sample contains the 35,488 respondents from twenty-six OECD countries who answered questions about paid parental leave offerings and for whom we were able to construct indicators of country-level characteristics, based on OECD and World Bank data. The twenty-six 
OECD countries included in our analyses are Australia, Austria, Belgium, Canada, Czech Republic, Denmark, Finland, France, Germany, Hungary, Iceland, Ireland, Japan, South Korea, Mexico, the Netherlands, Norway, Poland, Slovak Republic, Slovenia, Spain, Sweden, Switzerland, Turkey, the United Kingdom, and the United States.

An average of 1,365 individuals per country are in the sample. Missing data is modest; $70 \%$ of our sample contains no missing data and only about $5 \%$ of the sample has missing values for more than two of the variables that are used in the analysis. We use multiple imputation with chained equations over ten imputations to address missing data on the individual-level predictor variables after accounting for different country contexts; the results are similar with the use of listwise deletion of missing data.

\section{Dependent Variables}

Our dependent variables are formed from responses to queries about paid parental leave. The questionnaire presents the following scenario: "Consider a couple who both work full-time and now have a new born child. One of them stops working for some time to care for their child. Do you think there should be paid leave available and, if so, for how long?" Thus, respondents are first asked to indicate whether there should be paid leave available for this hypothetical couple and if so, how long the leave should be (in months). Further, respondents who supported leave availability are asked: "And who should pay for this leave? The government, the employer, both the government and the employer or other sources?" Based on the responses to these questions, we constructed three variables. Our first dependent variable represents support for any paid parental leave availability $(1=y e s)$. The second dependent variable is desired length of leave offerings, reported in months. Since respondents who did not support paid leave availability do not support any months of leave, by definition, they were assigned values of " 0 " 
months of desired length of leave offering. Finally, support for government funding of leave signifies whether respondents favored the offering of paid leave and having the government pay for some of its $\operatorname{cost}(1=y e s)$. Again, since respondents who did not support leave availability do not support government funding of it, by definition, they were assigned values of 0 for the dependent variable (i.e., no support for government funding of paid leave).

\section{Independent Variables}

Our main independent variables include gender $(1=$ female $)$ and gendered attitudes $(1=$ strongly disagree; 5 = strongly agree) about dual-earning, separate spheres, and intensive mothering. Dual-earner expectations are based on responses to the statement: "Both the husband and the wife should contribute to the household income." Separate spheres preferences are constructed from responses to: “Man's job is to earn money; a woman's job is to look after the home and family." Following previous research (e.g., Knoester and Li, 2021; Li et al., forthcoming; 2021) intensive mothering attitudes are created from responses to the statement: "All in all, family life suffers when the woman has a full-time job." These gendered attitudes are moderately correlated $(\mathrm{r}$ 's $=.17, .21$, and .45 ; separate spheres and intensive mothering attitudes are the most correlated); yet, tests for collinearity issues in our models indicate no apparent problems, based on variance inflation factors.

To tap family strains, we first use an ordinal variable $(1=$ strongly disagree; $5=$ strongly agree) that indicates the extent to which respondents think that children present a financial strain on parents. Second, we use averaged responses to four questions about whether one experiences $(1=y e s)$ different aspects of work-family conflict (e.g., family responsibilities lead to trouble concentrating at work; come home from work too tired to do chores, etc.) at least several times a month. 


\section{Other Individual- level Factors}

Other individual-level factors are utilized as control variables. Unpaid work is measured with four variables. These include the number of hours a week an individual and one's partner (if partnered) each spend on a) housework and b) care of family members; unpartnered respondents are allocated values of " 0 ” hours for a partner's unpaid work. All four variables are standardized in the analyses (i.e., mean of 0 ; standard deviation of 1). Paid work is measured with dummy variables indicating the number of hours per week that the respondent is employed: a) not working, b) working $<35$ hours per week, c) working 35-55 hours per week (used as reference category, based on evidence that this is typical among those employed), and d) working 55 hours or more per week. There is also an indicator of whether one has an employed (married or cohabiting) partner. Family context measures include relationship status variables (i.e., dummies for married, cohabiting, or single). Also, we account for the number of resident children under the age of 18 years old. The last individual-level variables represent years of age and education.

\section{Country-level Characteristics}

Finally, we include seven country-level covariates that reflect 2012 characteristics. These variables are created from OECD and World Bank data, except that we use the Economist Intelligence Unit Democracy Index 2012 for estimates of a country's level of democracy and the NationMaster website for a country's GDP per capita. Female empowerment is created by standardizing the percentage of female participation in higher education, the labor force, and the political arena; then, we take the mean of these values. Number of weeks of paid parental leave offered in each country contextualizes the generosity of paid parental leave offerings that existed in 2012 within the countries that respondents resided in. This is measured with two indicators: a) total number of paid weeks available (created based on all of mothers' potential opportunities), 
and b) total number of paid weeks reserved specifically for fathers. Country-level fertility rates, democracy levels, GDP per capita, and the percentage of GDP spent on family benefits (i.e., explicit family benefits spending such as cash transfers to families with children, services including child care and early childhood education, and financial support through the tax system such as with tax exemptions) are the final country-level covariates. The measures are centered at their respective grand means, for the multilevel analyses.

\section{Analytic Approach}

We use Stata 14 for our analyses and begin by examining descriptive statistics, including constructed difference scores between individuals' preferences for paid parental leave lengths and their country-level paid parental leave offerings (i.e., the sum of paid parental leave durations that mothers can take and father-reserved lengths of leave offerings, based on OECD documentations). Then, we employ hierarchical linear modeling (HLM) with random intercepts. We use multilevel binomial logistic regression in predicting support for paid parental leave availability and governmental funding. We use multilevel OLS regression to predict desired lengths of leave offerings. To test our hypothesized interaction effects, we introduce interaction terms between different attitudes about parenting roles into our full additive models for each dependent variable, in separate models. To better understand findings that are reported as odds ratios and are relevant to our hypotheses, we note predicted probabilities based on marginal effects calculations.

\section{Results}

\section{Descriptive Results}

The descriptive statistics for all variables are presented in Table 1 . The vast majority of respondents are in favor of the provision of paid parental leave; $86 \%$ reported that paid parental 
leave should be made available to a hypothetical couple in which both partners work full-time and share parentage of a newborn baby. The average preferred length of paid parental leave offering is nearly 13 months, but there is substantial variation in desired lengths as anticipated $(\mathrm{SD}=12)$. Finally, $74 \%$ of the respondents indicate that the government should be at least somewhat responsible for funding paid parental leaves. Thus, there is evidence of high levels of support for widespread and generous paid parental leave offerings but considerable disagreement in preferred lengths of leave offerings. Furthermore, as expected, women express significantly more support for widespread and generous paid leave offerings compared to men.

(Table 1 about here)

To more fully illustrate the cross-national similarities and variances in paid leave preferences, and how they are correlated with extant leave offerings, we also present scatter plots of within-country averages cross-matched to the total leave offerings for the respective countries, based on OECD summaries of total paid leave offerings that could be allocated to mothers plus father-reserved offerings, in Figures 1-3. Figure 1 and Figure 3 display similarities in showing relatively high levels of average support for paid leave availability and government funding of it across countries-and positive correlations ( $r=.44$ and .50 , respectively) between these leave preferences and extant leave offerings. Figure 2 again shows a positive correlation $(r=.61)$ between leave preferences and leave offerings, this time in regards to desired lengths of leave offerings, but it also highlights a good deal of variance in leave preferences and a pretty equal distribution of average preferences for leave offerings within countries that either exceed or fall short of extant offerings in the respective countries.

(Figure 1 about here)

(Figure 2 about here) 
(Figure 3 about here)

For further descriptive purposes, we also created an indicator of the extent to which individuals are satisfied with their country-level paid parental leave offerings by multiplying their desired months of paid leave offerings by 4.345 and then subtracting their country-level weeks of paid parental leave offerings from this. This calculation reveals a vast mismatch between desired lengths of leave offerings and extant country-level offerings. Nearly $90 \%$ of respondents desired lengths of leave offerings that were at least one month different than what was offered in their country; $64 \%$ of respondents desired lengths of leave offerings that were at least four months different than extant offerings. The average preference was to have leave offerings be about five weeks shorter than the extant offering, but as one might expect, respondents from countries with short leave offerings (e.g., U.S., Spain) were typically reporting preferences for increases and respondents from countries with long leave offerings (e.g., Finland, Hungary) were typically reporting preferences for decreases. Therefore, there is good reason to better understand individuals' preferences for paid parental leave offerings.

\section{Multilevel Model Results}

The results from the multilevel logistic regressions of paid parental leave availability are

presented in Model 1 of Table 2. We find evidence that gendered expectations and recognition of family strains are associated with support for paid parental leave availability, as hypothesized. Yet, because of the high levels of support for leave offerings, differences in predicted probabilities of support are very modest. Also, there is no evidence of interaction effects.

The odds for women endorsing paid parental leave are $24 \%$ higher than those for men $(\mathrm{OR}=1.24, p<.001)$; this translates into a .02 difference in predicted probabilities of support between men and women (i.e., .88 versus .90). Also, a one unit increase in support of dual-earner 
couple expectations is associated with a $15 \%$ increase in the odds of supporting paid parental leave $(\mathrm{OR}=1.15, p<.001)$; this results in a .06 difference in predicted probabilities of support when comparing the probabilities of those who strongly agree versus strongly disagree with dual-earning (i.e. .90 versus .84). Beyond this, proponents of traditionally gendered commitments to separate spheres of work (i.e., men in paid labor and women in unpaid domestic labor) are also less likely to support paid parental leave $(\mathrm{OR}=0.92, p<.01)$, translating into a .03 difference in predicted probabilities at the extremes. In regards to family strains, stronger agreement that parenting is expensive is associated with greater support for paid parental leave $(\mathrm{OR}=1.07 ; p<.001)$; also, reports of more work and family conflict are positively associated with supporting paid parental leave $(\mathrm{OR}=1.08 ; p<.01)$, as expected. But, differences are modest (.03 difference in predicted probability between the highest and lowest reports of family strains).

In Model 2 of Table 2, the additive multilevel linear regressions of desired lengths of paid parental leave are displayed. Again, there is no evidence of interaction effects involving parenting role attitudes. Still, as hypothesized, we find evidence that gendered expectations and the recognition of family strains predict paid parental leave preferences. Extant country-level paid parental leave offerings are associated with individuals' paid parental leave preferences as well.

Compared to men, women support nearly a month longer paid parental leave offerings $(b$ $=.93, p<.001)$. Also, intensive mothering attitudes are positively related to preferred lengths of paid parental leave offerings $(b=.40, p<.001)$. Additionally, recognizing children as expensive $(b=.23, p<.001)$ and experiencing more frequent work-family conflict $(b=.21, p<.01)$ are positively associated with preferred lengths of paid parental leave. Finally, there is support for 
the expectation that extant lengths of paid parental leave offerings in one's country are associated with one's desired lengths of paid parental leave offerings. Weeks of paid leave that a mother could conceivably take are positively associated with preferred lengths of leave offerings $(b=$ $.09, p<.001)$. Unexpectedly, weeks of paid leave that are reserved for fathers are negatively associated with preferred lengths of leave offerings $(b=-.16, p<.05)$. This may reflect the more egalitarian gendered cultures and more moderate durations of leave offerings that are present in countries that offer (more) paid paternity leaves - since there is a lack of encouragement for mothers to disproportionately take extended periods of paid leave and disengage from paid labor in these countries, on average (Boeckmann et al., 2015; Daly and Ferragina, 2018; Olivetti and Petrongolo, 2017).

Finally, results from regressions of attitudes about government funding of paid parental leave are presented in Model 3 of Table 2. We find evidence that gendered expectations and recognition of family strains are positively associated with support for government funding of leave offerings, as hypothesized. Yet, again, there is no evidence of interaction effects involving parenting role attitudes.

Dual-earning expectations $(\mathrm{OR}=1.08, p<.001)$ appear to increase the odds of endorsing some government funding of leaves. In contrast, separate spheres $(\mathrm{OR}=.91, p<.001)$ attitudes are negatively associated with support for government funding of paid parental leave. There is also evidence that recognizing the expenses involved in raising children $(\mathrm{OR}=1.04, p<.01)$ and reporting more frequent feelings of work-family conflict $(\mathrm{OR}=1.06, p<.001)$ lead to greater support for government funding of paid leave. Similar to the predicted probability results from supporting the provision of paid leave, differences in predicted probabilities are modest; for the 
extremes, they are .06 for dual-earning expectations (i.e., .72 versus .78), .07 for separate spheres attitudes, .03 for expense concerns, and .04 for work-family conflicts.

\section{Discussion}

The purpose of this study was to analyze public opinions about paid parental leave offerings from a large sample of individuals from many OECD countries, with a focus on documenting cross-national similarities and differences about paid leave attitudes and investigating how individuals' gendered expectations and family strains shape their leave preferences even when they are situated within substantially different country-level contexts. We first described patterns of support for paid leave availability, desired lengths of leave offerings, and government funding of leaves. Then, we highlighted the relevance of gendered expectations, family strains, and extant country-level leave offerings in predicting leave preferences.

First, we found overwhelming and common support for generous and widespread paid parental leave offerings. On average, $86 \%$ of respondents were in favor of having paid parental leave made available to a hypothetical couple comprised of two full-time working parents who had a newborn child. The average desired length of paid parental leave was nearly 13 months. About $74 \%$ of respondents believed not only that paid parental leave should be available, but that government funding should cover at least some of the cost of the paid leave. These results are in line with the institutionalized, widespread availability of at least some paid parental leave in nearly all of the countries in our sample and throughout the world. Yet, previous research has almost entirely focused on detailing leave offerings, uptake rates, and their presumed effects. Consequently, the findings of the present study fill a gap in knowledge about individuals' paid parental leave preferences in regards to availability, lengths, and funding throughout OECD countries (Ferragina, 2020; Koslowski et al., 2019; Li et al., 2021; Valarino et al., 2018). The 
findings bolster previous research that suggests, but has not documented, that there are quite universal preferences for widespread and generous paid parental leave offerings-even in the U.S., which is the only country in our analysis that does not have statutory paid parental leave offerings; although, notably, the U.S. is an outlier in having relatively low support for some government funding which may partially explain its lack of leave offerings (Li et al., forthcoming; 2021; Valarino et al., 2018).

Nevertheless, our descriptive results also suggest that many individual preferences for leave offerings are not being met, at the country-level. This finding hints at the complexities involved in the structuring of leave offerings and the apparent lack of unanimity about how to do so, across many different social contexts (Daly and Ferragina, 2018; Olivetti and Petrongolo, 2017). In fact, about $90 \%$ of respondents reported length of leave preferences that are over one month apart from their extant country-level offerings; about $64 \%$ reported preferences that are more than four months apart. These findings are consistent with, but also more precisely quantify, previous research on support for paid parental leave availability and its alignment with personal preferences. That is, there is a lack of consensus about exactly how to structure paid parental leave offerings and a great deal of disagreement with extant offerings at the country level, it seems (Li et al., forthcoming; 2021; Valarino et al., 2018).

Second, in accordance with our hypotheses, we found persistent evidence that gendered expectations were linked to paid parental leave preferences, even after accounting for different country-level contexts. For example, compared to men, women were more likely to support paid parental leave availability and they desired longer lengths of leave offerings. This is consistent with previous research, but extends these findings across many more social contexts, and further suggests that women are more likely than men to recognize the usefulness of paid parental leave 
for meeting their family and work aspirations and expectations. Indeed, parental leave-taking and shouldering the vast majority of domestic responsibilities are both still viewed as "women's issues," to a large extent. Also, women are much more likely to take a large share of paid parental leave, compared to men (Boeckmann et al., 2015; Hook, 2006; Li et al., 2021; O'Brien, 2013; Valarino et al., 2018). Thus, this finding highlights the importance of providing support to women to better enable them to fulfill both work and family responsibilities in societypresumably, through some combination of heightened support and encouragement from policies, employment practices, cultural expectations, and enhanced fathering commitments (Ferragina, 2020; Hook, 2006; O’Brien, 2013; Li et al., forthcoming; 2021; Valarino et al., 2018).

In addition, gendered expectations were apparent through the associations between multidimensional aspects of gendered parenting role attitudes and paid parental leave preferences. Although previous studies have typically relied on a single gender ideology construct (Grunow et al., 2018; Knight and Brinton, 2017; Valarino et al., 2018), we followed more recent research that is beginning to uncover the comprehensiveness and nuance of gendered attitudes (Cotter et al., 2011; Grunow et al., 2018; Knight and Brinton, 2017; Li et al., 2021; Petts et al., 2018). We found that dual-earner expectations are particularly linked to desires for the existence of paid parental leave availability, including the institutionalized support for it that accompanies some measure of government funding for leave offerings. Separate spheres preferences seem to lead to less common support for paid parental leave offerings. Intensive mothering beliefs seem to be especially significant in affecting desires for longer lengths of paid parental leave offerings. These findings are consistent with previous results that considered the implications of gendered attitudes for paid parental leave preferences, but help to further disentangle the relevance of multiple dimensions of attitudes about parenting roles ( $\mathrm{Li}$ et al., 
2021; Petts et al., 2018; Valarino et al., 2018). They also extend previous research on the importance of recognizing multiple dimensions of gender ideologies (Cotter et al., 2011; Davis and Greenstein, 2009; Grunow et al., 2018; Knight and Brinton, 2017). Yet, in the present study, we only find additive, independent associations between gendered parenting role attitudes and paid leave preferences.

Third, as hypothesized, our findings suggested that the realization of family strains is positively associated with support for more widespread and generous leave offerings. Recognizing the great expense in raising children and reporting higher levels of work-family conflict were positively associated with supporting paid leave availability, longer lengths of leave offerings, and government funding of leaves. These findings are consistent with previous research and extend our understanding of the influence of perceptions of need, and sometimes empathy, for espousing support for work-family policies (Duvander, 2014; Li et al., 2021; Valarino et al., 2018). Indeed, paid parental leave offerings are largely intended to address family well-being by alleviating family strains (Ferragina, 2020; Collins, 2019; O’Brien, 2009; Raub et al., 2018).

Finally, as hypothesized, our results offered evidence that extant lengths of paid paternity leave offerings in one's country are associated with individuals' paid leave preferences. This was apparent in the bivariate correlations between leave preferences and country-level offerings (i.e., Figures 1-3). There were also associations between country-level offerings and individuals' desired lengths of leave offerings in the multilevel regression results; although, we unexpectedly found that paid leave that is reserved for fathers is negatively associated with individuals' preferred lengths of leave offerings. We suspect that this is a function of more gender egalitarian 
goals for explicit family policies leading to more moderate leave offerings at the country level, on average (Ferragina, 2020; Olivetti and Petrongolo, 2017).

There are limitations of this research to note. Unfortunately, we are unable to assess the implications of country-level contexts in influencing individual attitudes to the extent that we would like. These associations are complicated, difficult to compare cross-nationally, and assumed to be bi-directional in that paid parental leave attitudes shape country-level contexts, and vice-versa (Campbell, 2012; Brooks and Manza, 2006; Li et al., 2021; Valarino et al., 2018). Future research could benefit from longitudinal analyses; however, previous and subsequent ISSP modules on family and changing gender roles do not contain the same extensive set of questions on parental leave. Also, more complete considerations of how leave offerings may be structured and experienced are warranted-for example, our leave preferences measures do not explicitly reference features such as job protection, reimbursement rates, and the presence of other relevant features of explicit family policies that may shape leave preferences (Daly and Ferragina, 2018; Ferragina, 2020). In addition, we do not disentangle individuals' preferences for paid maternity leave availability and paternity leave availability in the present study nor can we obtain complete understandings of how gendered expectations may matter for leave preferences with the limited measures that we can employ, here. Gendered dynamics and support for different types of leave require more detailed and substantial attention than we could devote within the current study (Li et al., 2021; Valarino et al., 2018). Finally, we are unable to adequately consider the potential influences of social desirability bias, personal experiences, personal ideals, and aspirations for work-family balances - especially vis-à-vis one's partner. Occupational structures, characteristics, and workplace dynamics are also expected to be relevant 
to how people encounter and think about paid parental leave policies and availability. Future research should explore these considerations.

Still, the results from this study are notable and recognize high levels of support from around the world for paid parental leave availability, relatively long lengths of paid leave offerings, and government funding for leave offerings. Additionally, the results seem to demonstrate the various ways in which support for paid parental leave offerings are shaped by gendered expectations. Family strains and country-level leave offerings also seem to consistently matter.

\section{Conclusion}

In light of these findings about common desires for widespread and generous paid leave offerings, and previous empirical evidence demonstrating the benefits of paid leave, there seems to be good reason for countries throughout the world to ensure that they offer them. In fact, as of 2012, the majority of respondents from virtually every country in our OECD sample endorsed at least three months of paid parental leave for a full-time dual-earning couple who had a newborn child (50\% of respondents from Mexico endorsed three months of paid leave) — and this amount of paid leave was made available to residents in every country in our sample, and throughout the entire OECD, except for those in the U.S. This makes it particularly striking that despite longstanding public opinion support for paid parental leave availability, and even $3+$ months of desired leave offerings, only the U.S., the wealthiest OECD country, does not offer any statutory paid parental leave nearly a decade later. Relatively little support among U.S. residents for some government funding of paid leaves, combined with various forms of obstructionism, resistance to taxation, and political gridlock, has appeared to prevent this supported policy—and the benefits that it offers - from being implemented (Knoester and Li, 2021; Li et al., forthcoming; 2021). Of 
course, the public opinion evidence presented in this study and previous research on the benefits of (paid) leave-taking suggest that the U.S. should implement a paid leave policy. The findings from this study also suggest that some government funding is an important mechanism for widely disseminating benefits, such as paid parental leave, to a population (Knoester and $\mathrm{Li}$, 2021; Li et al., forthcoming; 2021).

Yet, ongoing trends including the development of less traditional gender attitudes and increases in education, age-cohort replacements, dual-earner family structures, work-family conflict, childrearing expenses, democratization, female power and representation, and countries with low fertility offer further challenges to finding appropriate balances between simply generous and widespread leave offerings and packages of family policies that make good use of a country's resources and do not result in undue or inappropriate pressures and expectations to uphold traditionally gendered divisions of labor (Cotter et al., 2004; 2011; Daly and Ferragina, 2018; Ferragina, 2019; 2020; Ferragina and Seeleib-Kaiser, 2014; Goldscheider et al., 2015). In contrast to the challenges in the U.S. context and residents' push for minimal levels of paid leave, residents in some other countries (e.g., Austria, Czech Republic, Slovakia) reported preferences for more than two years of paid parental leave offerings, typically—which offers a different set of challenges and negotiations for instituting appropriate and agreed upon paid leave policies.

Indeed, parental leave opportunities seem to have numerous benefits for families but the structuring of them, in combination with other explicit family policies, can lead to many different consequences - particularly in regards to gendered behaviors, inequalities in the divisions of domestic and paid labor, and the abilities of women to be treated equally in their paid work pursuits (Ferragina, 2020; Isaacs et al., 2017; Li et al., forthcoming; 2021; Stancyzk, 2016). 
Therefore, there is a need to further research parental leave preferences, policies, and consequences. Societies that are able to meet the needs and desires of their members have the potential to markedly improve the quality of life, and expand considerations of different workfamily arrangements, for all (Ferragina, 2020; Pedulla and Thébaud, 2015; Thébaud and Pedulla, 2016). 


\section{References}

Acker J (1990) Hierarchies, jobs, bodies: A theory of gendered organizations. Gender \& Society $4: 139-158$.

Aitken Z, Garrett CC, Hewitt B, Keogh L, Hocking JS and Kavanagh AM (2015) The maternal health outcomes of paid maternity leave: A systematic review. Social Science and Medicine 130:32-41.

Akgunduz YE and Plantenga J (2013) Labour market effects of parental leave in Europe. Cambridge Journal of Economics 37(4):845-862.

Avendano M, Berkman LF, Brugiavini A and Pasini G (2015) The long-run effect of maternity leave benefits on mental health: Evidence from European countries. Social Science \& Medicine 132:45-53.

Bianchi SM, Robinson JP and Milkie M (2006) Changing Rhythms of American Family Life. New York: Russell Sage.

Biddle BJ (1986) Recent developments in role theory. Annual Review of Sociology 12(1):6792.

Blekesaune M and Quadagno J (2003) Public attitudes toward welfare state politics: A comparative analysis of 24 nations. European Sociological Review 19(5):415-27.

Boeckmann I, Misra J and Budig, MJ (2015) Cultural and institutional factors shaping mothers' employment and working hours in postindustrial countries. Social Forces 93(4):13011333.

Brooks C and Manza J (2006) Why do welfare states persist? The Journal of Polities 68(4):816-27. 
Budig MJ, Misra J and Boeckmann I (2015) Work-family policy trade-offs for mothers? Unpacking the cross-national variation in motherhood earnings penalties. Work and Occupations 43(2):119-177.

Campbell AL (2012). Policy makes mass politics. Annual Review of Political Science 15:333351.

Chatterji P and Markowitz S (2012) Family leave after childbirth and the mental health of new mothers. Journal of Mental Health Policy and Economics 15(2): 61-76.

Collins C (2019) Making motherhood work: How women manage careers and caregiving. Princeton, NJ: Princeton University Press.

Cooklin AR, Rowe HJ and Fisher JRW (2012) Paid parental leave supports breastfeeding and mother-infant relationship: A prospective investigation of maternal postpartum employment. Australian and New Zealand Journal of Public Health 36(3):249-56.

Cotter DA, Hermsen JM and Vanneman R (2004) Gender Inequality at Work. New York: Russell Sage Foundation.

Cotter DA, Hermsen, JM and Vanneman R (2011) The end of the gender revolution? Gender role attitudes from 1977 to 2008. American Journal of Sociology 117:259-289.

Craig L and Mullan K (2010) Parenthood, gender and work-family time in the United States, Australia, Italy, France, and Denmark. Journal of Marriage and Family 72:1344-1361.

Daly M and Ferragina E (2018) Family policy in high-income countries: Five decades of development. Journal of European Social Policy 28(3):255-270.

Davis SN and Greenstein TN (2009) Gender ideology: Components, predictors, and consequences. Annual Review of Sociology 35:87-105. 
Duvander A (2014) How long should parental leave be? Attitudes to gender equality, family, and work as determinants of women's and men's parental leave in Sweden. Journal of Family Issues 35:909-926.

Ferragina E (2019) The political economy of family policy expansion. Review of International Political Economy 26(6):1238-1265.

Ferragina E (2020) Family policy and women's employment outcomes in 45 high-income countries: a systematic qualitative review of 238 comparative and national studies. Social Policy \& Administration 54(7):1016-1066.

Ferragina E and Seeleib-Kaiser M (2015) Understanding the expansion of family policy in rich OECD Countries. Social Politics 22(1):1-37.

Gangl M and Ziefle A (2015) The making of a good woman: Extended parental leave entitlements and mothers' work commitment in Germany. American Journal of Sociology 121:511-563.

Goldscheider F, Bernhardt E and Lappegård T (2015) The gender revolution: A framework for understanding changing family and demographic behavior. Population and Development Review 41(2):207-39.

Goode WJ (1960) A theory of role strain. American Sociological Review 25(4):483-496.

Grunow D, Begall K and Buchler S (2018) Gender ideologies in Europe: A multidimensional framework. Journal of Marriage and Family 80:42-60.

Haas L and Hwang CP (2008) The impact of taking parental leave on fathers' participation in childcare and relationships with children: Lessons from Sweden. Community, Work \& Family 11(1):85-104. 
Haas L and Hwang CP (2019) Workplace support and European fathers' use of state policies promoting share childcare. Community, Work \& Family 22:1-22.

Hays S (1996). The Cultural Contradictions of Motherhood. New Haven, CT: Yale University Press.

Hook JL (2006) Care in context: Men's unpaid work in 20 countries, 1965-2003. American Sociological Review 71(4):639-60.

International Labour Organization (ILO) (2014) Maternity and paternity at work: Law and practice across the world. Geneva: International Labour Organization.

Isaacs J, Healy O and Peters HE (2017) Paid family leave in the United States: Time for a new national policy. Center on Labor, Human Services, and Population. Washington, D.C.: The Urban Institute.

Keck W and Saraceno C (2013) The impact of different social-policy frameworks on social inequalities among women in the European Union: The labour-market participation of mothers. Social Politics: International Studies in Gender, State \& Society 20(3):297-328.

Knight CR and Brinton MC (2017) One egalitarianism or several? Two decades of gender-role attitude change in Europe. American Journal of Sociology 122:1485-1532.

Knoester C and Fields V (2020) Mother-child engagement in sports and outdoor activities: Intensive mothering, purposive leisure, and implications for health and relationship closeness. International Review for the Sociology of Sport 55(7):933-952.

Knoester C and Li Q (2021) Preferences for paid paternity leave availability, lengths of leave offerings, and government funding of paternity leaves in the U.S. Online first in Sociological Perspectives. doi: 10.1177/07311214211001892

Koslowski A, Blum S, Dobrotić I, Macht, A and Moss P (2019) 15th International Review 
of Leave Policies and Related Research. Pp. 1-519 in International Network on Leave Policies and Research.

Li, Q, Knoester C, and Petts RJ. Forthcoming. Attitudes about paid parental leave in the U.S. Sociological Focus

Li, Q, Knoester C and Petts RJ (2021) Cross-national attitudes about paid parental leave offerings for fathers. Online first in Social Science Research doi:10.1016/j.ssresearch.2021.102540

Manza J and Cook FL (2002) A democratic policy? Three views of policy responsiveness to public opinion in the United States. American Politics Research 30(6):630-67.

Naldini M, Pavolini E and Solera C (2016) Female employment and elderly care: The role of care policies and culture in 21 European countries. Work, Employment and Society 30:607-630.

O’Brien M (2009) Fathers, parental leave policies, and infant quality of life: International perspectives and policy impact. The ANNALS of the American Academy of Political and Social Science 624:190-213.

O’Brien M (2013) Fitting fathers into work-family policies: International challenges in turbulent times. International Journal of Sociology and Social Policy 33:542-564.

Olivetti C and Petrongolo B (2017) The economic consequences of family policies: Lessons from a century of legislation in high-income countries. Journal of Economic Perspectives 31(1):205-230.

Pedulla DS, and Thébaud S (2015) Can we finish the revolution? Gender, workfamily ideals, and institutional constraint. American Sociological Review 
80(1):116-39.

Pettit, B and Hook, JL (2005) The structure of women's employment in comparative perspective. Social Forces 84(2): 779-801.

Petts RJ, Knoester C and Li Q (2018) Paternity leave-taking in the United States. Community, Work \& Family DOI: 10.1080/13668803.2018.1471589.

Pragg B and Knoester C (2017) Parental leave use among disadvantaged fathers. Journal of Family Issues 38:1157-1185.

Raub A, Nandi A, Earle A, Chorny NDG, Wong E, Chung, P, Batra P, Schickedanz A, Bose B, Jou J, Franken D and Heymann J (2018) Paid parental leave: A detailed look at approaches across OECD countries. WORLD Policy Analysis Center, Los Angeles, CA.

Ridgeway CL (2009) Framed before we know it. Gender \& Society 23:145-160.

Risman BJ (1998) Gender vertigo: American families in transition. New Haven: Yale University Press.

Scholz E, Juzt R, Edlund J, Öun I and Braun M (2014) ISSP 2012 Family and Changing Gender Roles IV: Questionnaire Development (Technical Reports No. 19). Mannheim, Germany: GESIS - Leibniz Institute for the Social Sciences.

Senior J (2014) All Joy and No Fun: The paradox of modern parenthood. New York: Harper Collins.

Stancyzk AB (2016) Paid family leave may reduce poverty following a birth: Evidence from California. The Employment Instability, Family Wellbeing, and Social Policy Network. Chicago: University of Chicago.

Stearns J (2015) The effects of paid maternity leave: Evidence from temporary disability insurance. Journal of Health Economics 43:85-102. 
Stier H, Epstein NL and Braun M (2001) Welfare regimes, family supportive policies, and women's employment along the life course. American Journal of Sociology 106:17311760.

Tanaka S (2005) Parental leave and child health across OECD Countries. The Economic Journal 115:F7-F28.

Thébaud S and Pedulla DS (2016) Masculinity and the stalled revolution: How gender ideologies and norms shape young men's responses to work family policies. Gender \& Society 30(4):590-617.

Valarino I, Duvander A, Haas L and Neyer G (2018) Exploring leave policy preferences: A Comparison of Austria, Sweden, Switzerland, and the United States. Social Politics: International Studies in Gender, State \& Society 25(1):118-47.

West C and Zimmerman DH (1987) Doing gender. Gender \& Society 1:125-151.

Winter NJG (2008) Dangerous Frames: How ideas about race \& gender shape public opinion. Chicago: University of Chicago Press.

World Bank Group (2018) Women, Business and the Law 2018. Washington, D.C.: World Bank.

Yavorsky JE, Dush CMK, and Schoppe-Sullivan SJ (2015) The production of inequality: The gender division of labor across the transition to parenthood. Journal of Marriage and Family 77(3):662-79. 
Table 1. Descriptive statistics for all variables used in the analysis

\begin{tabular}{|c|c|c|c|c|}
\hline & Full Sample & Male & Female & $p$ for difference \\
\hline Dependent variables & $M(S D)$ & $M(S D)$ & $M(S D)$ & \\
\hline Support for paid parental leave & 86.02 & 84.09 & 87.58 & $* * *$ \\
\hline Desired length of paid parental leave & 12.77 & 12.09 & 13.35 & $* * *$ \\
\hline & $(12.28)$ & $(12.16)$ & $(12.36)$ & \\
\hline $\begin{array}{l}\text { Support for government to pay for parental leave } \\
\text { Gendered expectations }\end{array}$ & 74.13 & 73.49 & 74.68 & $* * *$ \\
\hline Female & 53.96 & & & \\
\hline Dual-earner couples & $\begin{array}{c}3.98 \\
(0.98)\end{array}$ & $\begin{array}{c}3.90 \\
(1.00)\end{array}$ & $\begin{array}{l}4.05 \\
(0.97)\end{array}$ & $* * *$ \\
\hline Separate spheres & $\begin{array}{c}2.41 \\
(1.28)\end{array}$ & $\begin{array}{c}2.56 \\
(1.28)\end{array}$ & $\begin{array}{c}2.29 \\
(1.27)\end{array}$ & $* * *$ \\
\hline Intensive mothering & $\begin{array}{c}2.82 \\
(1.30)\end{array}$ & $\begin{array}{c}2.86 \\
(1.27)\end{array}$ & $\begin{array}{c}2.78 \\
(1.32)\end{array}$ & $* * *$ \\
\hline Family strains & & & & \\
\hline Having children is expensive & $\begin{array}{c}3.01 \\
(1.14)\end{array}$ & $\begin{array}{c}2.99 \\
(1.13)\end{array}$ & $\begin{array}{c}3.03 \\
(1.15)\end{array}$ & $*$ \\
\hline Work-family conflict & $\begin{array}{c}0.60 \\
(1.00)\end{array}$ & $\begin{array}{c}0.61 \\
(0.99)\end{array}$ & $\begin{array}{c}0.59 \\
(1.01)\end{array}$ & \\
\hline Other individual-level factors & & & & \\
\hline Weekly hours spent on housework & $\begin{array}{l}-0.01 \\
(1.00)\end{array}$ & $\begin{array}{l}-0.30 \\
(0.74)\end{array}$ & $\begin{array}{c}0.26 \\
(1.08)\end{array}$ & $* * *$ \\
\hline Weekly hours spent on care for family members & $\begin{array}{l}-0.01 \\
(1.00)\end{array}$ & $\begin{array}{l}-0.20 \\
(0.73)\end{array}$ & $\begin{array}{c}0.17 \\
(1.16)\end{array}$ & $* * *$ \\
\hline Spouse weekly hours spent on housework & $\begin{array}{c}0.02 \\
(1.00)\end{array}$ & $\begin{array}{c}0.38 \\
(1.20)\end{array}$ & $\begin{array}{l}-0.29 \\
(0.66)\end{array}$ & $* * *$ \\
\hline Spouse weekly hours on care for family members & $\begin{array}{c}0.02 \\
(1.00)\end{array}$ & $\begin{array}{c}0.16 \\
(1.13)\end{array}$ & $\begin{array}{l}-0.10 \\
(0.87)\end{array}$ & $* * *$ \\
\hline (Works 35-55 hrs per week in paid labor) & 38.07 & 44.89 & 32.26 & Ref \\
\hline Works $<35$ hrs per week in paid labor & 11.97 & 6.25 & 16.84 & $* * *$ \\
\hline Works $>55$ hrs per week in paid labor & 6.32 & 9.99 & 3.19 & $* * *$ \\
\hline Not working & 43.64 & 38.87 & 47.70 & $* * *$ \\
\hline Partner employed & 39.25 & 35.03 & 42.86 & $* * *$ \\
\hline (Married) & 55.99 & 59.39 & 53.09 & Ref \\
\hline Cohabiting & 9.12 & 8.82 & 9.38 & $* * *$ \\
\hline Single & 34.89 & 31.79 & 37.53 & $* * *$ \\
\hline Number of residential children in household & $\begin{array}{c}0.60 \\
(1.03)\end{array}$ & $\begin{array}{c}0.55 \\
(0.99)\end{array}$ & $\begin{array}{c}0.64 \\
(1.06)\end{array}$ & $* * *$ \\
\hline Age & $\begin{array}{c}48.86 \\
(17.40)\end{array}$ & $\begin{array}{c}49.42 \\
(17.48)\end{array}$ & $\begin{array}{c}48.39 \\
(17.33)\end{array}$ & $* * *$ \\
\hline Education & $\begin{array}{l}12.68 \\
(4.25)\end{array}$ & $\begin{array}{l}12.72 \\
(4.16)\end{array}$ & $\begin{array}{l}12.65 \\
(4.33)\end{array}$ & $* *$ \\
\hline Country-level characteristics & & & & \\
\hline Female empowerment & $\begin{array}{l}-0.01 \\
(0.77)\end{array}$ & & & \\
\hline Weeks of paid parental leave available & $\begin{array}{c}52.10 \\
(42.71)\end{array}$ & & & \\
\hline Weeks of paid leave reserved for fathers & $\begin{array}{c}8.48 \\
(13.92)\end{array}$ & & & \\
\hline Fertility rate & $\begin{array}{c}1.70 \\
(0.29)\end{array}$ & & & \\
\hline Democratic level & $\begin{array}{c}8.27 \\
(0.96)\end{array}$ & & & \\
\hline GDP per capita/ 10,000 & $\begin{array}{c}4.00 \\
(2.11)\end{array}$ & & & \\
\hline Percent GDP on family benefits & $\begin{array}{c}2.14 \\
(0.99) \\
\end{array}$ & & & \\
\hline N (Individual) & 35,488 & 16,337 & 19,151 & \\
\hline $\mathrm{N}$ (Countries) & 26 & 26 & 26 & \\
\hline
\end{tabular}


Table 2. Multilevel regression results predicting support, desired length, and governmental funding for paid parental leave

\begin{tabular}{|c|c|c|c|c|c|c|c|c|c|}
\hline & \multicolumn{3}{|c|}{ (1) } & \multicolumn{3}{|c|}{ (2) } & \multicolumn{3}{|c|}{ (3) } \\
\hline & \multicolumn{3}{|c|}{ Support } & \multicolumn{3}{|c|}{ Length } & \multicolumn{3}{|c|}{ Funding } \\
\hline & $O R$ & & SE & $b$ & & SE & $O R$ & & SE \\
\hline \multicolumn{10}{|l|}{ Gendered expectations } \\
\hline Female & 1.24 & $* * *$ & 0.05 & 0.93 & $* * *$ & 0.11 & 1.02 & & 0.03 \\
\hline Dual-earner couples & 1.15 & $* * *$ & 0.02 & -0.03 & & 0.05 & 1.08 & $* * *$ & 0.01 \\
\hline Separate Spheres & 0.92 & $* * *$ & 0.01 & -0.06 & & 0.05 & 0.91 & $* * *$ & 0.01 \\
\hline Intensive mothering & 0.99 & & 0.02 & 0.40 & $* * *$ & 0.04 & 0.99 & & 0.01 \\
\hline \multicolumn{10}{|l|}{ Family strains } \\
\hline Having children is expensive & 1.07 & $* * *$ & 0.02 & 0.23 & $* * *$ & 0.04 & 1.04 & $* *$ & 0.01 \\
\hline Work-family conflict & 1.08 & $* * *$ & 0.02 & 0.21 & $* * *$ & 0.06 & 1.06 & $* * *$ & 0.02 \\
\hline \multicolumn{10}{|l|}{ Other Individual-level Factors } \\
\hline Weekly housework hours & 1.02 & & 0.02 & 0.33 & $* * *$ & 0.06 & 1.02 & & 0.02 \\
\hline Weekly family care hours & 1.19 & $* * *$ & 0.03 & 0.39 & $* * *$ & 0.06 & 1.13 & $* * *$ & 0.02 \\
\hline Spouse weekly housework hours & 1.02 & & 0.02 & 0.14 & $*$ & 0.07 & 1.02 & & 0.02 \\
\hline Spouse weekly family care hours & 0.98 & & 0.02 & 0.14 & $*$ & 0.06 & 1.01 & & 0.02 \\
\hline \multicolumn{10}{|l|}{ Employment status } \\
\hline Works $<35$ hrs per week in paid labor ${ }^{\mathrm{a}}$ & 1.04 & & 0.06 & 0.15 & & 0.17 & 1.01 & & 0.05 \\
\hline Works $>55$ hrs per week in paid labor ${ }^{\mathrm{a}}$ & 0.78 & $* * *$ & 0.05 & -0.42 & & 0.22 & 0.89 & $*$ & 0.05 \\
\hline Not working ${ }^{\mathrm{a}}$ & 1.01 & & 0.05 & -0.33 & $*$ & 0.14 & 0.88 & $* *$ & 0.03 \\
\hline Partner employed & 0.97 & & 0.05 & 0.23 & & 0.15 & 1.01 & & 0.04 \\
\hline \multicolumn{10}{|l|}{ Marital status } \\
\hline Cohabiting ${ }^{\mathrm{b}}$ & 1.13 & & 0.08 & -0.22 & & 0.18 & 1.08 & & 0.06 \\
\hline Single $^{\mathrm{b}}$ & 0.78 & $* * *$ & 0.04 & -0.49 & $* *$ & 0.16 & 0.84 & $* * *$ & 0.04 \\
\hline Number of residential children & 1.03 & & 0.02 & 0.32 & $* * *$ & 0.06 & 1.06 & $* * *$ & 0.02 \\
\hline Age & 0.99 & $* * *$ & 0.00 & -0.02 & $* * *$ & 0.00 & 0.99 & $* * *$ & 0.00 \\
\hline Education & 1.02 & $* * *$ & 0.00 & 0.03 & $*$ & 0.01 & 1.03 & $* * *$ & 0.00 \\
\hline \multicolumn{10}{|l|}{ Country-level characteristics } \\
\hline Female empowerment & 0.54 & $*$ & 0.17 & -6.10 & $* *$ & 2.34 & 0.56 & $*$ & 0.14 \\
\hline Weeks of paid parental leave available & 1.00 & & 0.00 & 0.09 & $* * *$ & 0.02 & 1.00 & & 0.00 \\
\hline Weeks of paid leave reserved for father & 1.00 & & 0.01 & -0.16 & $*$ & 0.07 & 1.00 & & 0.01 \\
\hline Fertility rate & 0.32 & $*$ & 0.16 & -9.79 & $* *$ & 3,73 & 0.47 & & 0.18 \\
\hline Democratic level & 2.04 & $*$ & 0.66 & 5.80 & $*$ & 2.47 & 1.91 & $*$ & 0.49 \\
\hline GDP per capita/10,000 & 0.82 & $*$ & 0.08 & -1.39 & & 0.75 & 0.87 & & 0.07 \\
\hline Percent GDP on family benefits & 1.01 & & 0.17 & 0.96 & & 1.26 & 1.15 & & 0.15 \\
\hline $\mathrm{N}$ (Individual) & \multicolumn{3}{|c|}{35,488} & \multicolumn{3}{|c|}{35,488} & \multicolumn{3}{|c|}{33,5488} \\
\hline $\mathrm{N}$ (Countries) & \multicolumn{3}{|c|}{26} & \multicolumn{3}{|c|}{26} & \multicolumn{3}{|c|}{26} \\
\hline
\end{tabular}




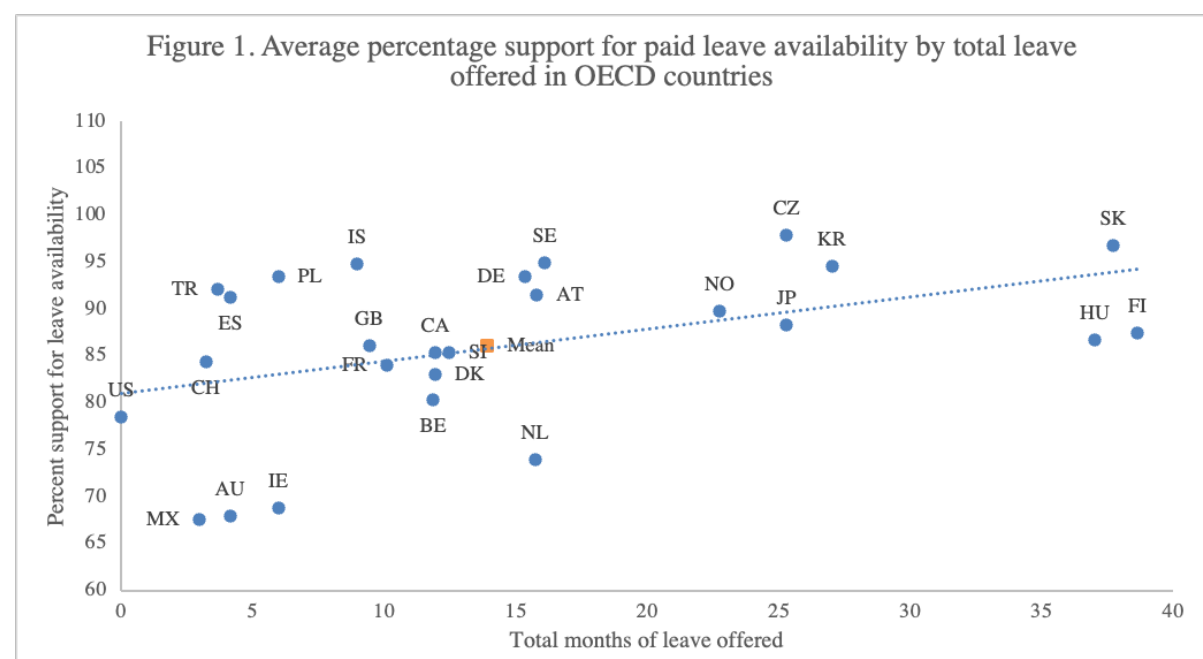

Note: $\mathrm{AT}=$ Austria, $\mathrm{AU}=$ Australia, $\mathrm{BE}=$ Belgium, $\mathrm{CA}=$ Canada, $\mathrm{CH}=$ Switzerland, $\mathrm{CZ}=$ Czech Republic $, \mathrm{DE}=\mathrm{Germany}, \mathrm{DK}=\mathrm{Denmark}, \mathrm{ES}=\mathrm{Spain}, \mathrm{FI}=$ Finland, FR $=$ France, $\mathrm{GB}=$ Great Britain, $\mathrm{HU}=$ Hungary, $\mathrm{IE}=$ Ireland, IS = Iceland, JP $=$ Japan, KR $=$ South Korea, MX= Mexico, NL $=\mathrm{Netherlands,} \mathrm{NO}=$ Norway, $\mathrm{PL}=$ Poland, $\mathrm{SE}=$ Sweden, $\mathrm{SI}=$ Slovenia, $\mathrm{SK}=$ Slovakia, $\mathrm{TR}=$ Turkey, $\mathrm{US}=$ United States

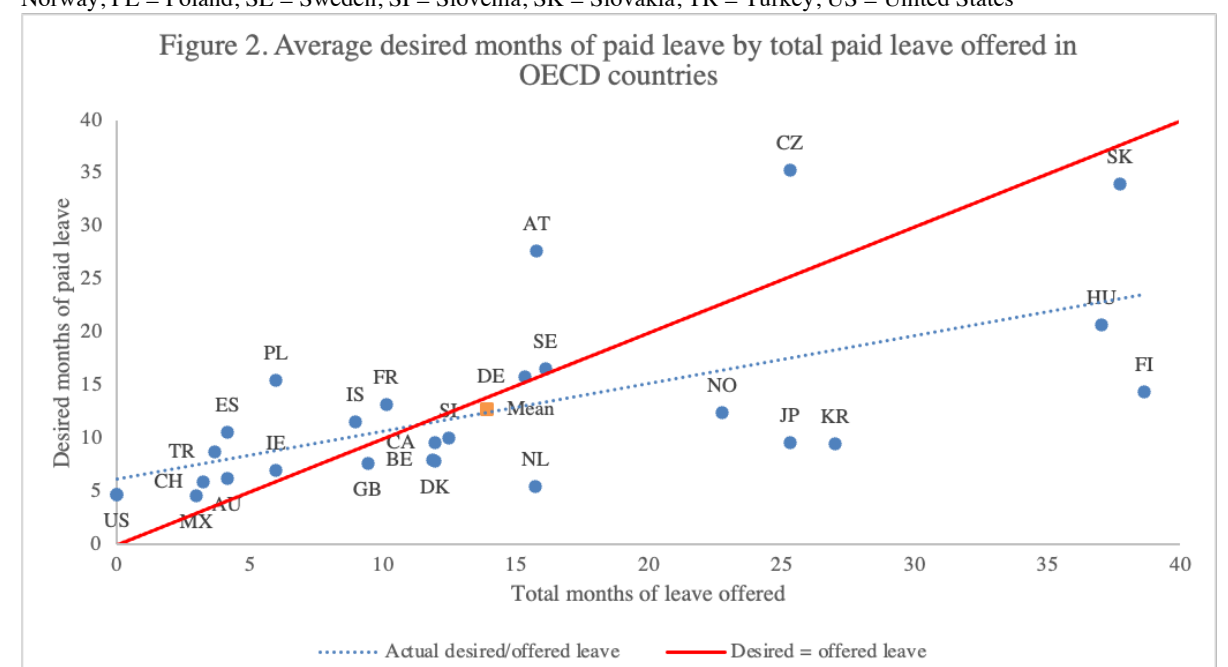

Note: $\mathrm{AT}=$ Austria, $\mathrm{AU}=$ Australia, $\mathrm{BE}=$ Belgium, $\mathrm{CA}=$ Canada, $\mathrm{CH}=$ Switzerland, $\mathrm{CZ}=\mathrm{Czech}$ Republic $, \mathrm{DE}=\mathrm{Germany}, \mathrm{DK}=\mathrm{Denmark}, \mathrm{ES}=\mathrm{Spain}, \mathrm{FI}=$ Finland, FR = France, GB = Great Britain, HU = Hungary, IE = Ireland, IS = Iceland, JP = Japan, KR = South Korea, MX= Mexico, NL = Netherlands, NO = Norway, $\mathrm{PL}=$ Poland, $\mathrm{SE}=$ Sweden, $\mathrm{SI}=$ Slovenia, $\mathrm{SK}=$ Slovakia, $\mathrm{TR}=$ Turkey, $\mathrm{US}=$ United States

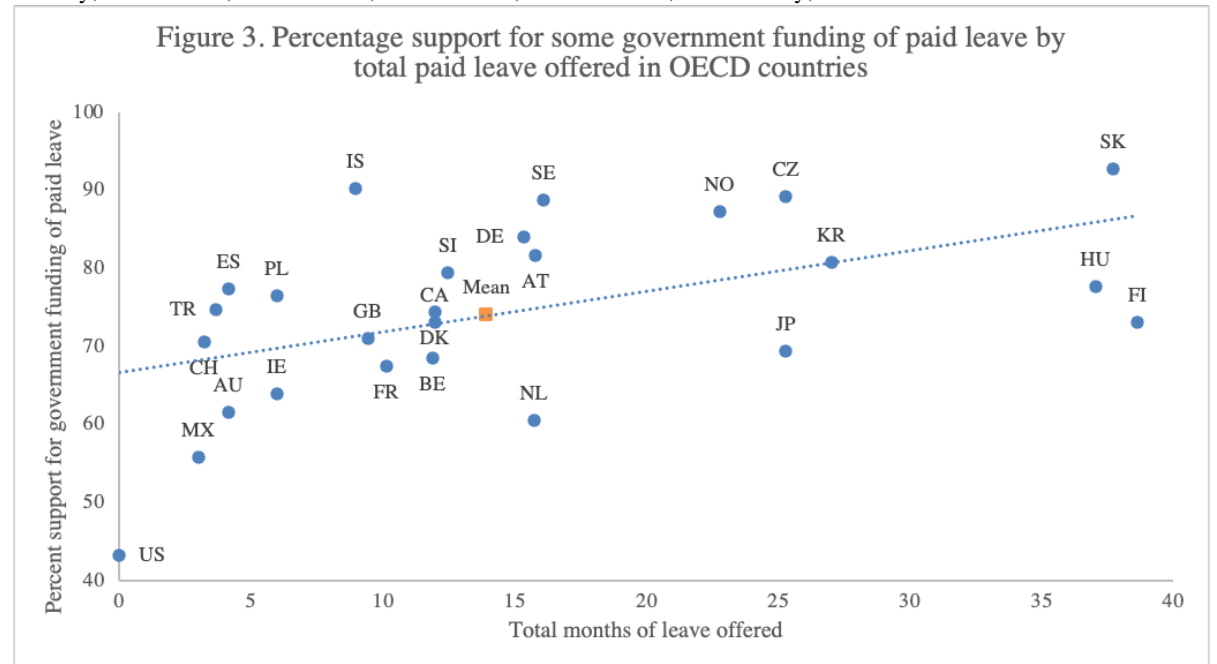


Note: $\mathrm{AT}=$ Austria, $\mathrm{AU}=$ Australia, $\mathrm{BE}=$ Belgium, $\mathrm{CA}=$ Canada, $\mathrm{CH}=$ Switzerland, $\mathrm{CZ}=$ Czech Republic, $\mathrm{DE}=\mathrm{Germany}, \mathrm{DK}=\mathrm{Denmark}, \mathrm{ES}=\mathrm{Spain}, \mathrm{FI}=$

Finland, FR $=$ France, $\mathrm{GB}=$ Great Britain, $\mathrm{HU}=$ Hungary, $\mathrm{IE}=$ Ireland, IS = Iceland, $\mathrm{JP}=\mathrm{Japan}, \mathrm{KR}=$ South Korea, MX= Mexico, NL $=\mathrm{Netherlands,} \mathrm{NO}=$

Norway, $\mathrm{PL}=$ Poland, $\mathrm{SE}=$ Sweden, $\mathrm{SI}=$ Slovenia, $\mathrm{SK}=$ Slovakia, $\mathrm{TR}=$ Turkey, $\mathrm{US}=$ United States 